\title{
Fake fur, fruit leather, and ferrofluids: Challenges to managing a materials library in the Middle East
}

Amy J. Andres

Virginia Commonwealth University in Qatar, ajandres@vcu.edu

Richard J. Lombard

Follow this and additional works at: https://scholarscompass.vcu.edu/libraries_pubs

Part of the Library and Information Science Commons

Accepted version - Institutional Repository

\section{Downloaded from}

https://scholarscompass.vcu.edu/libraries_pubs/66

This Article is brought to you for free and open access by the VCU Libraries at VCU Scholars Compass. It has been accepted for inclusion in VCU Libraries Faculty and Staff Publications by an authorized administrator of VCU Scholars Compass. For more information, please contact libcompass@vcu.edu. 


\title{
Fake fur, fruit leather, and ferrofluids: Challenges to managing a materials library in the Middle East
}

\author{
Richard Lombard AND Amy Andres
}

\begin{abstract}
$\mathrm{T}$ he Materials Library at Virginia Commonwealth University in Qatar is the only one of its kind in the Arab Gulf region. The library's mission is to provide students and faculty with access to various industries' most innovative materials and products. But collection efforts are frequently challenged by the school's geographical location. How can a diverse and eclectic materials collection develop and expand in the face of strict customs regulations, exorbitant shipping costs, and, most recently, a political crisis that has severely restricted the country's airspace and shipping routes? A supportive administration and a creative approach to materials procurement have helped the library become an academic and community hub for the research and creative productivity of students, faculty, and local artists and designers.
\end{abstract}

\section{Introduction}

Qatar, a sovereign Arab country with a population of just over 2.7 million, ${ }^{1}$ has risen dramatically in stature over the course of recent years. In the mid 1990s, with the aim of helping the nation diversify its economy away from oil production, the country's emir, His Highness Sheikh Hamad bin Khalifa Al Thani, founded the Qatar Foundation for Education, Science and Community Development. ${ }^{2}$ Qatar Foundation (QF), a private, non-profit organization, was established with the mission to build a sustainable knowledge-based economy through the promotion of education, science, and research. ${ }^{3}$ To increase educational and research opportunities within the country, a major initiative of Qatar Foundation was the establishment of Education City.

Education City is a 2,500-acre campus located in the capital city of Doha. It is home to the country's national library, one Qatari university, and seven branch campuses of international universities. ${ }^{4}$ The international universities were invited to Education City by Qatar Foundation, with each school offering a unique range of degrees and programs.

One of the American international branch campuses is Virginia Commonwealth University, School of the Arts. In 1997, Qatar Foundation invited Virginia Commonwealth University to establish a school of arts and design. It was established under the name of Shaqab College of Design Arts (SCODA) and classes in fashion design, graphic design, and interior design began in September of 1998. Today Virginia Commonwealth University in Qatar (VCUQ) enrolls 363 students, representing 41 nationalities, and offers a Bachelor of Arts major in art history and a Bachelor of Fine Arts in fashion design, graphic design, interior design, and painting and printmaking. VCUO also offers a Master of Fine Arts in design.
1. "Population Newsletter." Ministry of Development Planning and Statistics, State of Qatar. Accessed June 29, 2017. http:// www.mdps.gov.qa/en/statistics1/ pages/topicslisting.aspx?parent= Population\&child=Population 2. "Qatar National Vision 2030." Ministry of Development Planning and Statistics, State of Qatar. Accessed June 18, 2017. http:// www.mdps.gov.qa/en/qnv1/ Pages/default.aspx

3. "Mission Statement." Qatar Foundation. Accessed July 14, 2017. https://www.qf.org.qa/ about/about

4. Hamad Bin Khalifa University is a Qatari university located within Education City. The American universities include Virginia Commonwealth University, Weill Cornell Medicine, Carnegie Mellon, Texas A\&M, and Northwestern University. University College London is the British university.

\section{The libraries of VCUO}

The research and creative endeavors of VCUO students and faculty are supported by two libraries housed within the VCUO building: a traditional research library, and a materials library. The traditional library holds a print collection of circa 40,000 volumes that is focused primarily on arts of the Islamic empires and 
contemporary Arab art and design. The library also holds special collections of artist's books from the Arab region and rare books related to the history, art, and culture of Qatar and the Arabian Peninsula. Additionally, the library provides online access to the digital library of its home campus library in Richmond, Virginia, which includes more than 80,000 electronic journals and approximately 660,000 e-books. The library also has an inter-library loan Memorandum of Agreement with all of the Education City branch campus libraries and with the library at Qatar University, the country's largest university.

\section{Why a materials library?}

The Materials Library at VCUO houses a collection of thousands of material samples from manufacturers around the world, material and product information catalogs, and examples of innovative materials use in consumer products. The resource also serves as an information point for local suppliers and fabricators.

The rationale for such a resource is clear: in order to understand materials, one has to actually interact with them. They are a truly haptic experience, and the true 'interface' of the built environment: everything that we touch and smell, and much of what we see and hear, is because of materials.

As a designer, it is of critical importance to know what you are making your product out of - whether it's a dress, a book, a chair, or a car. Lending tremendous influence to everything from manufacture to sustainability to performance, materials take design off of the page (or the screen) and into the real world. How can one teach design without teaching materials?

Conversely, it is virtually impossible to learn about materials without touching them. What do we mean when we say 'soft'? There is furry soft, rubbery soft, foamy soft - the list goes on and on. To simply read the word on a page only gives a broad sense that a material is 'not hard'. One needs to touch materials in order to know how a final product will appear, feel, smell, not to mention perform.

Touch reveals simple things, like the difference between a newspaper and a magazine - they're both just words on a page, but the difference in feel conveys a very different message for both of them. The weight of a pen can transmit a significant message about the perceived quality of the firm whose name appears on it.

Materials also occupy a remarkably pivotal space for critical thinking. While most materials are created with a specific application in mind, there are often few restrictions in using any material for an 'alternate' purpose, opening up multiple venues for exploration and learning. A single material can inspire virtually every discipline, whether it be through its origins, its appearance, or its capabilities. Additionally, unlike printed information, a material's qualities are more immediately transmitted and more inherently understood within a short period of time.

\section{The VCUO Materials Library}

The establishment of the materials library would ultimately wait for both the creation of the VCUQ MFA program in 2009, as well as the opening of a new building that would more than double the size of the school's facilities. In 2010, after the successful search for a curator for the materials library, and the allocation of some $100 \mathrm{~m}^{2}$ of classroom space in the new building, the development of the materials library began in earnest.

The goal of the first curator was to create a space that would be useful as quickly as possible, something that would have sufficient material - of any kind (sample, brochure, finished product) - to engage with the majority of students. To that end, the decision was made to lease material panels from Material ConneXion on an ongoing basis. While this decision was initially made to populate the resource with a diverse collection of innovative materials, and one that could serve as an entry point for the online database to which the school subscribed, it also highlighted what would become an obstacle in the future development of the resource: international shipping. Through the subscription arrangement with Material ConneXion, VCUQ was able to bring in hundreds of materials in a single shipment, a single customs clearance process, and a single invoice. 
The Material ConneXion samples are pre-mounted on panels that were simple (and inexpensive) to mount on the walls of the space, much as they are in the company's libraries around the world. The display presents visitors with an immediate palate of ideas, as well as a simple organizational tool as the panels are easy to reorganize, remove, and replace. The materials in this collection represent some of the latest and most innovative developments in commerciallyavailable materials for design. This would be the 'push' part of the collection: materials that were significant in the industry, but might not necessarily have immediate use or application by the students. They were there to inspire.

While the true 'pull' component of the resource - the requests from students and faculty - would come over time, an initial scouring of local firms and trade shows supplied a collection of samples directly relevant to the majors of the school: textiles for fashion, paper samples for graphic design, and stone and tile samples for interior design students (Fig. 1) (Fig. 2).

\section{Key challenge: Organization}

At the creation of the VCUO Materials Library, the collection was organized by broad material 'class' - Polymers, Metals, Glasses, Ceramics, etc. While there were some conceptual flaws in this - glasses and cements are, technically, ceramics - it was a logical classification structure, and easy to communicate to both library staff and users. However, especially in the arrangement of the wall panels, the scheme proved problematic.

Due to the general uniformity of the provided samples within a class of materials, the walls became clusters of white sheets of plastic, clear pieces of glass, gray pieces of metal, with some shots of color here and there. It was those bursts of 'difference' amidst the 'sameness' that attracted all the attention and provided the best entrance to discussion about what was needed in a particular case. Students did not care what a material was made of so much as what it looked like.

Through a few iterative changes, the most immediately-engaging organizational structure for the wall panels emerged: color (Fig. 3). As virtually all visitors to the library had - either consciously or unconsciously - a desired color palate for their project, that was always one of the first things that caught their eye. As a result, the entrance wall of the library was organized according to the color spectrum, from Ultra Violet to Infrared, and all visitors were immediately presented with a graspable assemblage of materials of every category.

Another organizational issue that emerged was the absolute reluctance of library users to engage with anything organized on a shelf. The initial layout of the resource was similar to that of a traditional book-based library, with shelves of

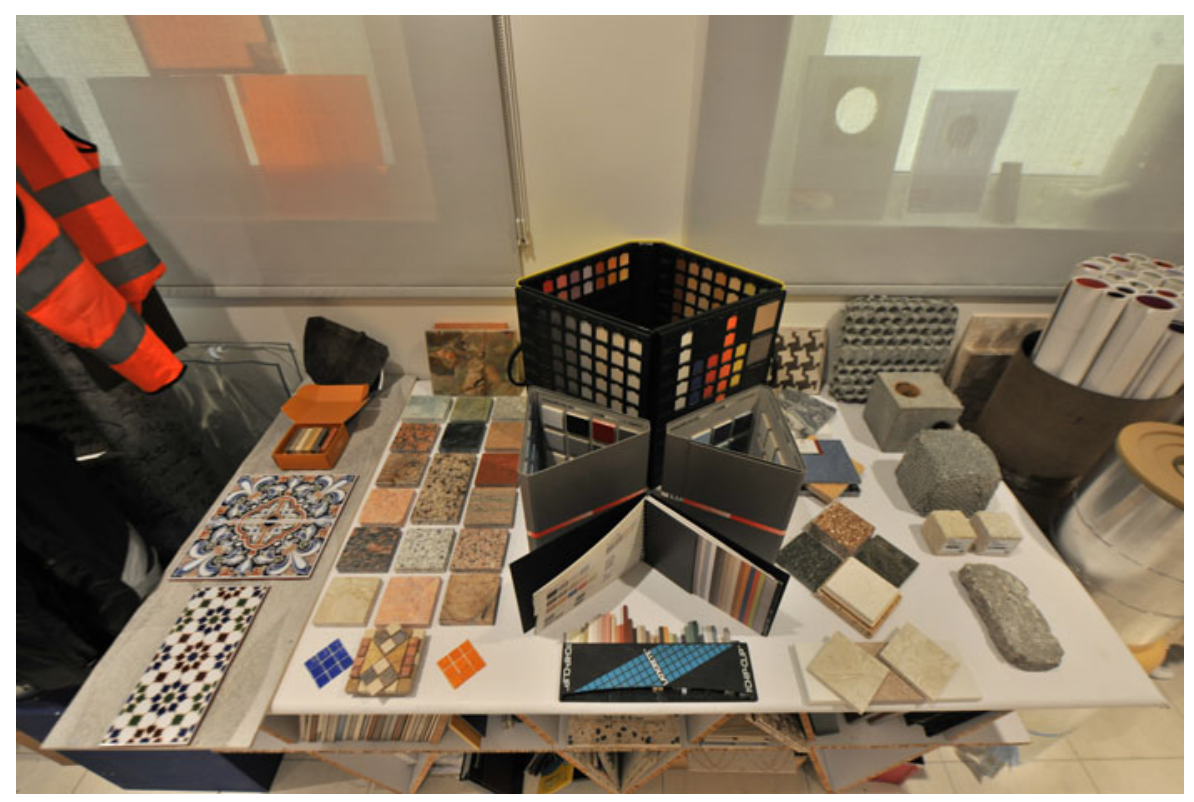

Fig. 1. VCUQ Materials Library. Credit: Islam Shehab 


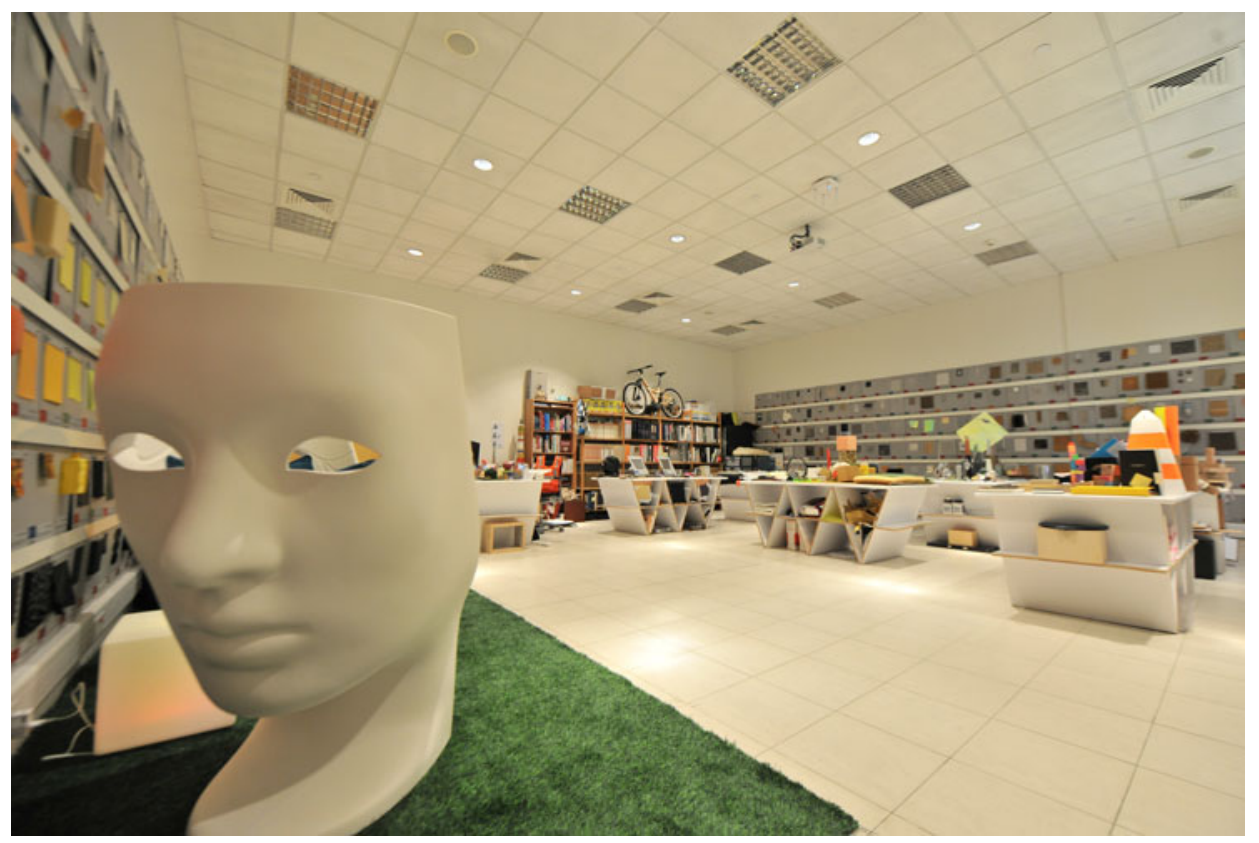

Fig. 2. Materials on display in the VCUO Materials Library. Credit: Islam Shehab

material samples and printed materials dominating the space, augmented with the wall panels and some tables for curated display of products. This was seen as the most logical and space-efficient manner to present the materials; however, users engaged solely with those materials on the walls and on the tables - those that were immediately accessible to their eyes, and their hands.

More and more tables were brought into the Materials Library to allow for more and more samples to be, quite literally, 'at hand'. These materials were grouped by both material type, and by application, to present both similarities and varieties at the same time. Despite the difficulties of maintaining order samples were being handled and moved at a much higher rate - the impact on student comprehension was significant. Ultimately, it was decided to design and fabricate bespoke tables to present and store the materials samples, and a series of innovative cardboard tables were created to serve in this capacity. Traditional

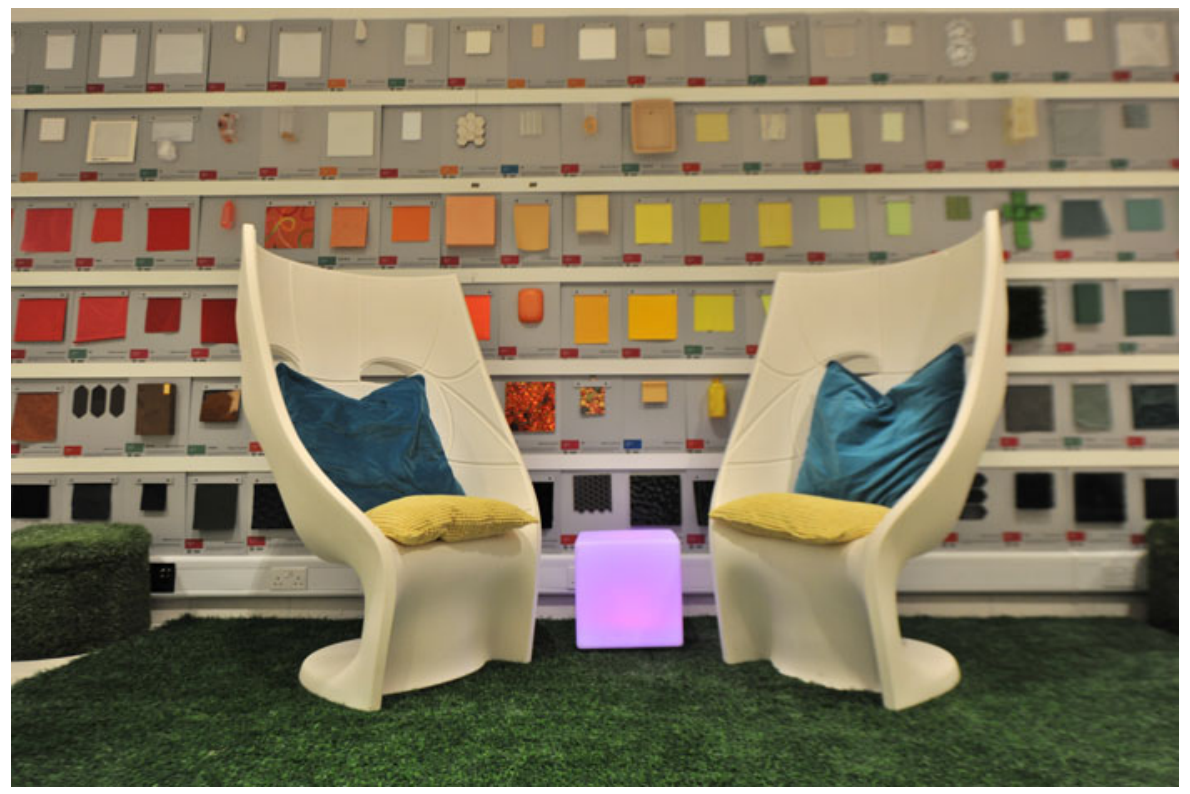

Fig. 3. Material ConneXion panels on display in the VCUO Materials Library. Credit: Islam Shehab 
shelving is still used, but solely for printed catalogues, trend reports, and redundant/overflow manufacturer-provided sample books.

\section{Sourcing materials and inventory control}

While Material ConneXion continues to provide the Materials Library with an annual delivery of a curated materials collection, the library also develops its collection through other sourcing activities. Developing a collection to represent local, regional, and international innovations in materials has always presented a range of unique challenges. Such challenges include the difficulty of identifying (often transient) Doha-based vendors, navigating international customs clearances for materials sourced from abroad, sustaining professional relationships and networks across thousands of miles and, more recently, strategizing delivery of goods in spite of restrictions imposed on regional airspace and shipping lanes.

From the time the library was established, it has been important that it sustain a local network of vendors, suppliers, and fabricators. The importance of such a network lends convenience to VCUQ students who need to purchase supplies, but to identify such businesses remains an ongoing challenge.

In 2010 when the library was established, and even today, many Doha businesses did not have an Internet presence; and those that do have a website may have their information published in Arabic only (and logically so). There is also the issue of physical addresses. It was not until 2012 that Qatar's Centre for Geographic Information Systems began systematically to identify city zones, street names, and building numbers. Even today, street addresses are seldom used and locations are found by landmark (e.g. 'located near XYZ roundabout' or 'behind the $X Y Z$ ministry offices opposite $X Y Z$ restaurant'). This means that a GPS navigation system can only take you so far in locating a business, necessitating a significant amount of individual time and energy to procure local materials or to identify a local fabricator.

In 2014, the curator of the Materials Library began building and mapping a geo-database of local businesses and fabricators. The database, which is an ongoing project, pinpoints local businesses on a local map and identifies their product and/or services by keyword. The database is searchable by natural language or by the select authority-controlled subject headings also used to manage the library's inventory and circulation systems.

In 2016, Qatar customs regulations were modified and tightened, thereby creating an additional level of complexity for the import of materials. The library assumes all costs related to international shipping and customs fees, so its operating budget was impacted directly by some of the new customs fees and duties. While some traditional materials (e.g. fabrics) are still fairly easy to ship to Qatar; other items that may seem conventional (e.g. magnets) are difficult to import; while the less conventional materials that may sought for the library's collection (e.g. gun powder) have become almost impossible to procure.

This problem was compounded in June of 2017 when some of Qatar's regional neighbors imposed a set of blockades against the country. While the Qatari government has found solutions to the major ramifications of the blockade (e.g. food import), there remain some issues that impact the daily lives of its citizens and residents, such as travel bans for Qatari citizens and the delayed arrival of imported goods.

The shipping delays will also impact student project planning, which has been an ongoing issue with material sourcing. Even prior to the recent changes, the vagaries of shipment times to the region played havoc with class and project deadlines. It is impossible to overstate the challenges that VCUO students and faculty face, compared to their counterparts in cities where art supplies stores exist. There is often no 'Plan B' in Doha, and even the most conservative, 'worst case' plan can be foiled by a courier, a customs agent, or a missing stamp on an invoice that was unnecessary just a week before. The library staff will continue to work closely with both students and faculty to advise them of the changes while also drastically revising procurement timelines to minimize impact on student productivity.

The materials library plays an instructional role in the procurement process, as it is a critical part of any project plan. It also plays a critical logistical role. Many of our students do not have credit cards that are required for online shopping, or addresses to which a package can be shipped. This means that it is not enough 
for the library to provide them with a link to a vendor website, and the library must also serve as an intermediary for student purchases.

Supported by a strict set of guidelines, the library has coordinated with the staff of the school's book shop to establish a system where the student can prepay for materials; in turn, the shop will order the materials on the student's behalf. As previously stated, when students require materials for a design project, it is ideal if those materials can be sourced locally, but if the materials can only be sourced outside of Qatar, the library is prepared to lend support.

Given the logistical challenges faced by the library, it is no surprise that shipping costs are a constant issue to be managed by the library director. Fiscal responsibility is an ongoing priority; however, shipping costs continue to rise, and currently account for approximately one-third of the library's procurement budget. This is another reason why sourcing locally is critical to the sustainability of the library's collection.

\title{
Conclusion
}

While the VCUO Materials Library will continue to face logistical challenges related to collection development, the overall mission of the library to engage, educate, and inspire students, faculty, and local practitioners remains intact. The library staff continues to enhance the learning opportunities of the VCUO community by finding creative ways to source materials from Qatar, the region, and from around the world.

\section{Richard Lombard}

New York, New York

United States

Email: rjlombard@matterofimportance.com

\author{
Amy Andres \\ Director of Libraries \\ Virginia Commonwealth University in Qatar \\ PO Box 8095, Al Luqta Street \\ Education City \\ Doha \\ Qatar \\ Email: ajandres@vcu.edu
}

